\title{
Systematic Review of the Prevalence and Incidence of Intellectual Disabilities: Current Trends and Issues
}

\author{
Katherine McKenzie $^{1} \cdot$ Meagan Milton $^{1} \cdot$ Glenys Smith $^{1} \cdot$ Hélène Ouellette-Kuntz ${ }^{1,2}$
}

Published online: 15 April 2016

(C) Springer International Publishing Switzerland 2016

\begin{abstract}
The prevalence of intellectual disabilities is often quoted at $1 \%$. A meta-analysis of articles published between 1980 and 2009 confirmed this prevalence. Changes in diagnostic practices, population characteristics, and exposure to known risk factors in recent years place this estimate in question and make it imperative to examine more recent studies of prevalence and incidence. Twenty relevant articles were obtained from five databases (PubMed, Embase, PsycInfo, Cochrane, and MEDLINE), published between 2010 and 2015. Most studies $(n=17)$ only reported prevalence estimates, while two provided incidence estimates. Various methodologies were applied, with the majority of studies $(n=16)$ using administrative data. Heterogeneity in study settings, methodologies, age groups, and case definitions contributed to a range of prevalence estimates (0.05 to $1.55 \%)$. Future research should include reproducible and consistent
\end{abstract}

This article is part of the Topical Collection on Intellectual Disability

Hélène Ouellette-Kuntz

helene.kuntz@queensu.ca

Katherine McKenzie

k.mckenzie@queensu.ca

Meagan Milton

14mm62@queensu.ca

Glenys Smith

glenys.smith@queensu.ca

1 Department of Public Health Sciences, Queen's University, Kingston, ON K7L 3N6, Canada

2 Ongwanada, 191 Portsmouth Avenue, Kingston, ON K7M 8A6, Canada definitions of intellectual disabilities, provide age-specific estimates, and monitor changes in prevalence over time.

Keywords Prevalence $\cdot$ Incidence $\cdot$ Intellectual disability Developmental disability $\cdot$ Meta-analysis $\cdot$ Review

\section{Introduction}

Intellectual disabilities are lifelong conditions that manifest during the developmental years and are characterized by below-average general intellectual function and limitations in adaptive functioning [1]. In the 1970s, when diagnostic criteria focused on standardized intelligence quotient tests (IQ) cut-offs, it was estimated that $3 \%$ of annual births could be expected to "acquire" such disabilities at some point in their lives (incidence) [2]. This proportion corresponded to a cut-off of approximately 70 on a Gaussian curve for the distribution of intelligence scores. Using this cut-off, the proportion of a given population affected (prevalence) would also be $3 \%$. The recognition that IQ alone is not sufficient to diagnose intellectual disabilities, that intellectual disabilities manifest at different ages and under different conditions, and that there are identified causes of the disabilities has led to a reconsideration of both incidence and prevalence.

As incidence reflects risk in a population, recent focus has been on incidence of intellectual disabilities from specific known causes, such as genetic abnormalities, prenatal exposure to alcohol or infection, trauma during birth, early childhood infections, exposure to heavy metals, and severe malnutrition. Trend analyses, including those obtained through systematic reviews of the literature, contribute to the identification of changes in risk factors. In 2011, Maulik et al. published a systematic review and meta-analysis that evaluated studies of the prevalence of intellectual disabilities published between 
1980 and 2009 [3••]. The authors highlighted the variability of prevalence estimates across countries, age groups, and study design. Prevalence estimates were highest in low- and middleincome countries, in children/adolescents populations, and when psychological assessments were used to identify cases [3••]. They concluded that the best estimate of prevalence for that time period was $1 \%$.

Knowing the distribution of intellectual disabilities as a whole in the population (prevalence) informs service planning across multiple sectors from child and youth services, education, health, social services, and aging services. However, to understand variations in the occurrence of intellectual disabilities over time or place requires an appreciation of the shifts and differences in diagnostic practices, population characteristics, and exposure to known risk factors.

Over the past few decades, considerable shifts have occurred in diagnostic practices. While IQ tests are no longer sufficient to identify intellectual disabilities, they are still applied in conjunction with measures of adaptive functioning. IQ tests are subject to the Flynn effect [4], which refers to the steady and substantial increase in IQ in the population over the past century. To compensate, tests are re-normed and become more difficult, resulting in more individuals falling below an IQ of 70 after the test is re-normed [5]. Similarly, measures of adaptive and intellectual functioning, which are culturally based [6, 7], must also be re-normed as societal views and expectations of individuals with intellectual disabilities evolve. The Vineland Adaptive Behaviour Scales II, a commonly used measure of adaptive behavior, includes updated content about social expectations of tasks and living skills [8], which may alter diagnostic rates.

Changes in diagnostic criteria are often held responsible for the fluctuating prevalence estimates of intellectual disabilities, and in particular prevalence estimates of autism spectrum disorder - a condition associated with intellectual disabilities. Multiple revisions to two international classification systems, the Diagnostic and Statistical Manual (DSM) [9, 10] and the International Classification of Diseases (ICD) [11], have resulted in broadening and tightening of diagnostic criteria for intellectual disabilities, including the addition of adaptive functioning criteria to case identification [12], as well as for autism spectrum disorders $[13,14]$. One influential change to the diagnostic criteria for autism spectrum disorder is the allowable age of diagnosis: the specific age of onset at 3 years of age was removed in the most recent DSM (DSM-5) [15]. Furthermore, a proportion of the documented increases in the administrative prevalence of autism spectrum disorder corresponds to a drop in the administrative prevalence of other disabilities, most notably intellectual disabilities - a phenomenon known as diagnostic substitution [16, 17].

Another change related to diagnostic practices is the advent of prenatal diagnosis for some intellectual disabilities, namely, Down Syndrome (Trisomy 21), Edwards Syndrome (Trisomy
13), and Patau Syndrome (Trisomy 18) initially recommended for women over 35 years of age but now offered to all women [18-21]. Such technological advances may contribute to a decrease in the occurrence of intellectual disabilities in the population due to a high number of elected terminations of pregnancy. In a systematic review of termination rates following a definitive prenatal diagnosis of Down Syndrome, Natoli et al. (2012) reported a weighted mean termination rate of $67 \%$ among seven US-based population studies [22].

Changes or differences in population characteristics, including the average parental age, socioeconomic status, and sex ratios, can influence the prevalence and incidence of intellectual disabilities. Increasing maternal age has been identified as a risk factor for intellectual disabilities including Down Syndrome [23-25] and autism spectrum disorder [26]. Increasing paternal age is also identified as a risk factor for autism spectrum disorder [27]. Reviews demonstrating a doubling in the prevalence of intellectual disabilities in lowand middle-income countries compared to high-income countries suggest a role for socioeconomic status in the risk of intellectual disabilities $[1,3 \bullet \bullet, 28]$. In addition, a decreasing male-to-female ratio seen in autism spectrum disorder, likely due to increased rates of diagnosis in females, may be indicative of an overall increase in prevalence of the disorder [29, 30]. Given that between 40 and $61 \%$ of individuals with autism spectrum disorder are estimated to have intellectual disabilities [31, 32], this increasing prevalence may have associated implications for intellectual disabilities more broadly.

Finally, changes in exposure to risk factors associated with brain development can attenuate or increase the overall risk of intellectual disabilities in a population. These changes may be related to the application of risk reduction strategies such as education concerning consumption of alcohol during pregnancy, failure of preventive measures such as the recent lead contamination of drinking water in Flint, Michigan [33], or changes in the spread and/or virulence of infectious agents. The latter is exemplified by the recent spread of the Zika virus across northeastern Brazil and other nations, which has raised concerns about the risk of microcephaly and other congenital malformations in infants born to infected mothers and the subsequent intellectual disabilities associated with these malformations [34]. Such concerns are reminiscent of epidemics of rubella throughout the twentieth century, where congenital rubella syndrome increased the risk of a diagnosis of intellectual disabilities [35]. An understanding of such epidemics may explain some variation in the occurrence of intellectual disabilities prior to the introduction of rubella vaccines.

Considering the extensive collection of epidemiological factors that can influence the occurrence of intellectual disabilities, it is necessary to continue to systematically monitor trends and carefully review contemporary estimates. The 
purpose of the current review was to extend Maulik et al.'s work [3••] beyond 2009 .

\section{Methods}

The systematic review included the period 2010 to 2015. It involved searching PubMed, Embase, PsycInfo, Cochrane, and MEDLINE using both keywords and MeSH terms or Thesaurus words. The searches specified two elements: the population of interest (intellectual disability) and the outcome (prevalence and/or incidence) (Table 1). Articles known to the authors were also included as gray literature.

Articles were included if they represented original research on prevalence or incidence of intellectual disabilities in the underlying population. All age groups were included. To reduce the risk of under- or over-estimating prevalence or incidence, studies were excluded if (1) the estimates did not reflect all individuals with intellectual disabilities (e.g., focusing on individuals born prematurely, with chromosomal abnormalities, with autism), (2) the researchers only sampled from specific populations (e.g., individuals living in correctional facilities, visiting pediatric hospitals, or attending special schools), or (3) there was no report of prevalence for all levels of intellectual disabilities combined (e.g., only mild, moderate, or severe cases).

Articles were limited to those in English or French, and full-text articles. Study inclusion was not limited by study design (e.g., cross-sectional, cohort); however, studies that did not provide a case definition or that did not provide an adequate explanation of the methodology used to calculate prevalence or incidence were excluded.

Table 1 Example of search strategy

\begin{tabular}{ll}
\hline Elements & Search terms \\
\hline Population & intellectual impairment \\
& intellectual disabilit* \\
& intellectual dysfunction \\
& developmental disability* \\
& intellectual developmental disorder \\
& mental deficiency \\
& mental* retard* \\
& mental* handicap* \\
& mental* disab* \\
& mental insufficiency \\
& mental* impair* \\
& mental* subnormality \\
learning disability* & Prevalence \\
Outcome & Incidence \\
\hline
\end{tabular}

All articles retrieved through the databases were placed in a bibliographic data manager, where duplicates were removed. Titles and abstracts were reviewed by three reviewers (KM, GS, MM) to identify relevant articles. Full-text articles were retrieved, if available, and each article was reviewed by two reviewers. Two reviewers (KM, GS, MM, HOK) independently recorded inclusion and exclusion criteria. If reviewers disagreed, the eligibility of the study was discussed and a third reviewer made the final decision to include or exclude. References of the chosen studies were searched and included in the review if eligible.

Descriptive information was abstracted from each included article independently by two reviewers (KM, GS, MM, $\mathrm{HOK})$. If reviewers disagreed, the variable was discussed and consensus obtained before the data was entered into Microsoft Access 2013. Data included country, region, rurality, age group, age range, study type, data sources, diagnosis system or assessment instruments used, observation period, target population, survey/population size, and case definition. Reviewers also indicated if the observation period and target population were well defined. If studies provided a clear and operational case definition, cases were deemed reproducible (e.g., provided exact survey questions to identify cases, listed ICD codes). Prevalence or incidence estimates were recorded, by age, sex, and year, as applicable. Estimates obtained across studies are presented in figures to reflect differences by country, age, year, and method of data collection.

\section{Results}

A total of 3767 citations were identified across the five databases representing 2313 separate references. Three additional articles were identified by the authors, resulting in 2316 distinct citations. Articles were excluded upon abstract review $(n=2230)$ and once the full text was accessed $(n=63)$. As shown in Table 2, the most common reasons for exclusion were that the article was not about intellectual disabilities (often about developmental delay or disabilities in general), focused on developmental outcomes after a given exposure, or reported no estimate of occurrence in the population.

Data were extracted from 23 articles that met our inclusion criteria. During data extraction, it was determined that three articles did not provide a clear case definition [36-38]. Additionally, one article [39] reported on the same survey and provided the same prevalence estimates as another [40]. As a result, 20 articles are included in the review; one provides incidence estimates, one includes both prevalence and incidence estimates, and 17 provide prevalence estimates only (Fig. 1).

Table 3 provides a summary of the two articles reporting on incidence. The studies came from Sweden [41] and Denmark [42]. One study [41] was limited to the childhood period while 
Table 2 Reasons for article exclusion

\begin{tabular}{lll}
\hline Exclusion criteria (in hierarchical order) & Abstract & Articles \\
\hline Not about intellectual disabilities & 1176 & 18 \\
No prevalence or incidence estimates & 909 & 10 \\
Not in English & 0 & 1 \\
Not all levels of intellectual disability & 11 & 4 \\
Specific population (e.g., special school, premature & 49 & 8 \\
$\quad$ birth) & 82 & 3 \\
Specific sub-group of IDD & \\
Fragile X syndrome & 3 & - \\
Down syndrome & 4 & - \\
Autism spectrum disorder & 50 & - \\
Attention deficit hyperactivity disorder & 6 & - \\
Cerebral palsy & 5 & - \\
Other & 16 & - \\
Not an original article & 23 & 3 \\
\hline
\end{tabular}

${ }^{a}$ Abstracts could be excluded for including multiple sub-groups

the other extended to adulthood [39]. Both studies used administrative data although only one provided a comprehensive list of ICD codes used to identify individuals with intellectual disabilities [42]. The cumulative incidence reported for Denmark to age 50 was higher $(1.58 \%$ for males and $0.96 \%$ for females) [42] than that reported for Sweden overall $(0.62 \%)$ where individuals were followed to a median of 14 years [41]. The Swedish study also provided an incidence rate of 4.6 per 10,000 person-years (where person-years is the sum of the number of years each individual contributed to the study).

Table 4 provides a summary of the 18 articles that report prevalence. Three of these articles reported on multiple methodologies; as such, they are counted as distinct studies: Bielska et al. (2012) provide estimates derived from two different national household surveys [46], Lin et al. (2013) used three different case definitions [45 ${ }^{\circ}$, and Westerinen et al. (2014) provided prevalence estimates for three age groups based on distinct definitions for each [47].

Seven studies (from six articles) used national household surveys [40, 46, 48, 54, 56, 57] and 16 studies (from 12 articles) used administrative data (health, education, social services, or national registries) [42-44, 45•, 47, 49, 50• 51-53, 55]. Of the survey-based studies, three were from the United States $[48,54,56]$, and the others were from Canada $(n=2)$ [40], China $(n=1)$ [40], and India $(n=1)$ [57]; three reported
Fig. 1 Flow chart of articles included in review. ${ }^{*}$ See Table 1 for number of articles lost to each exclusion criteria

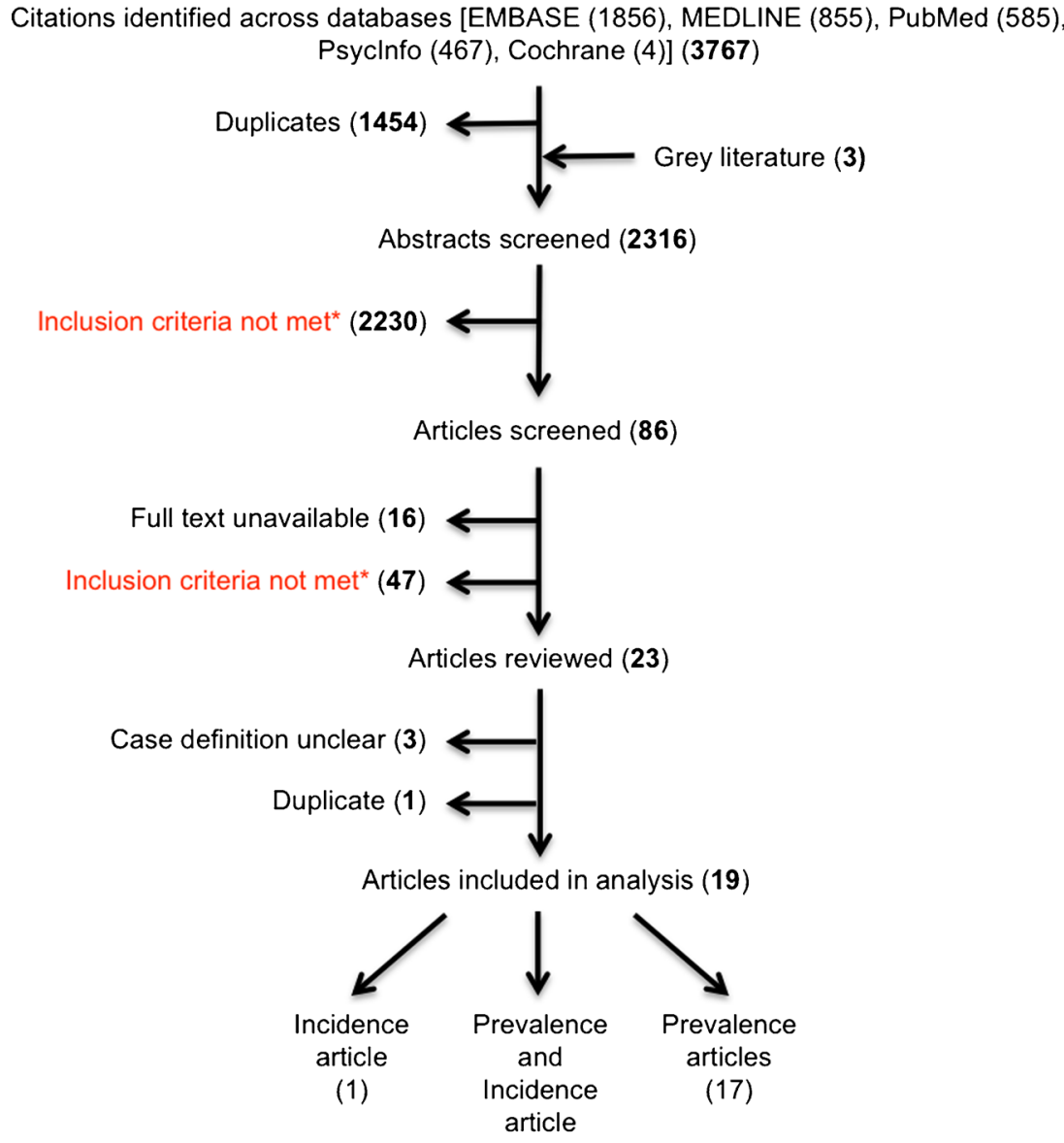

(1) 
on children/adolescents (age ranges 6-17, 0-18, 3-17) [48, $54,56]$, two on adults (age ranges $18+$ and 20+) [46], and two on children/adolescents and adults (age range $0+$ ) [40, 57]. The studies relying on administrative data were from seven different countries across North America (three from USA [32, 53, 55], three from Canada [45•]), Europe (three from Finland [47], one each from Denmark [42] and Norway [49]), and the Asia-Pacific region (two from Australia [43, 44], three from Taiwan [50•, 51, 52]); these were fairly evenly spread across studies of children/ adolescents $(n=6$; age ranges $0-15,3-17,8,6-17)[32,47$, $50 \bullet, 51-53]$, adults $(n=5$; age ranges $18+, 18-64$, and $65+)$ $[43,45 \cdot, 47]$, and both children/adolescents and adults $(n=5$; age ranges 6-19, 16-64, 0+, 3-21) [42, 44, 47, 49, 55].

The seven studies that relied on surveys all used slightly different questions to ascertain the presence of intellectual disabilities. Only three specifically asked if a medical professional had made the diagnosis [46, 48, 56]. In five instances, the questions listed examples of diagnoses [46, 48, 54, 56]. Eleven studies used a recognized classification system (ICD-8, 9, or 10; DSM-IV; AAMR) to identify the presence of intellectual disabilities in administrative data [32, 42, 44, 47, 49, 52]; some provided an extensive list of codes included $[45 \cdot$, 47]. Finally, five studies defined having intellectual disabilities as those who scored positive on psychological assessments $[50 \cdot 51]$, those who sought services for persons with intellectual disabilities [43], those who met a legal definition of intellectual disabilities [55], or those who received special education because of an intellectual disability [53].

As shown in Fig. 2, prevalence was highly variable across studies. Child/adolescent estimates ranged from $0.22 \%$ in 2007-2008 (USA) [54] to $1.55 \%$ in 1996 (USA) [32]. Adult estimates ranged from $0.05 \%$ in 2009 (Australia) [43] to $0.8 \%$ in 2009 (Canada) [45•]. Estimates that included both children/adolescents and adults ranged from $0.10 \%$ in 2000 (Denmark) [42] to $1.30 \%$ in 2005 (Australia) [44]. The earliest prevalence estimate reported was $1.2 \%$ for children/ adolescents and adults in China in 1987 [40] and the most recent was $0.66 \%$ for children/adolescents in the United States in 2012 [53]. There were no time trends observed when all estimates were considered. Seven studies provided prevalence estimates across multiple years $[32,40,48,51,53-55]$. Of these studies, one revealed an increase over time [51], three reported decreasing prevalence $[40,53,55]$, while three identified no time trend [32, 48, 54].

Six studies provided a breakdown of prevalence by sex [32, 46-48, 50•] (Fig. 3). All but one study [46] reported a higher prevalence in males. This anomaly was an estimate for adults based on a national 


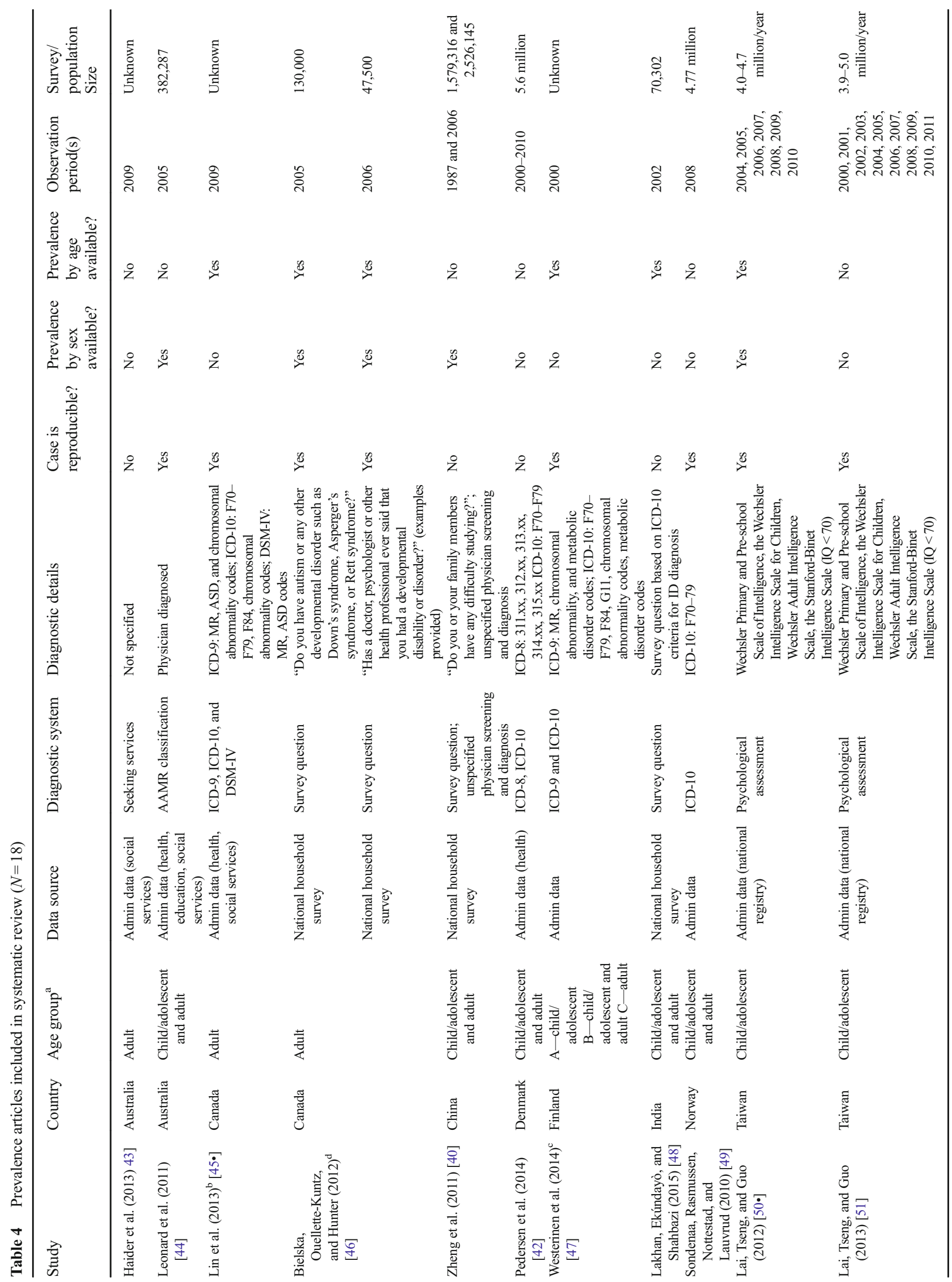




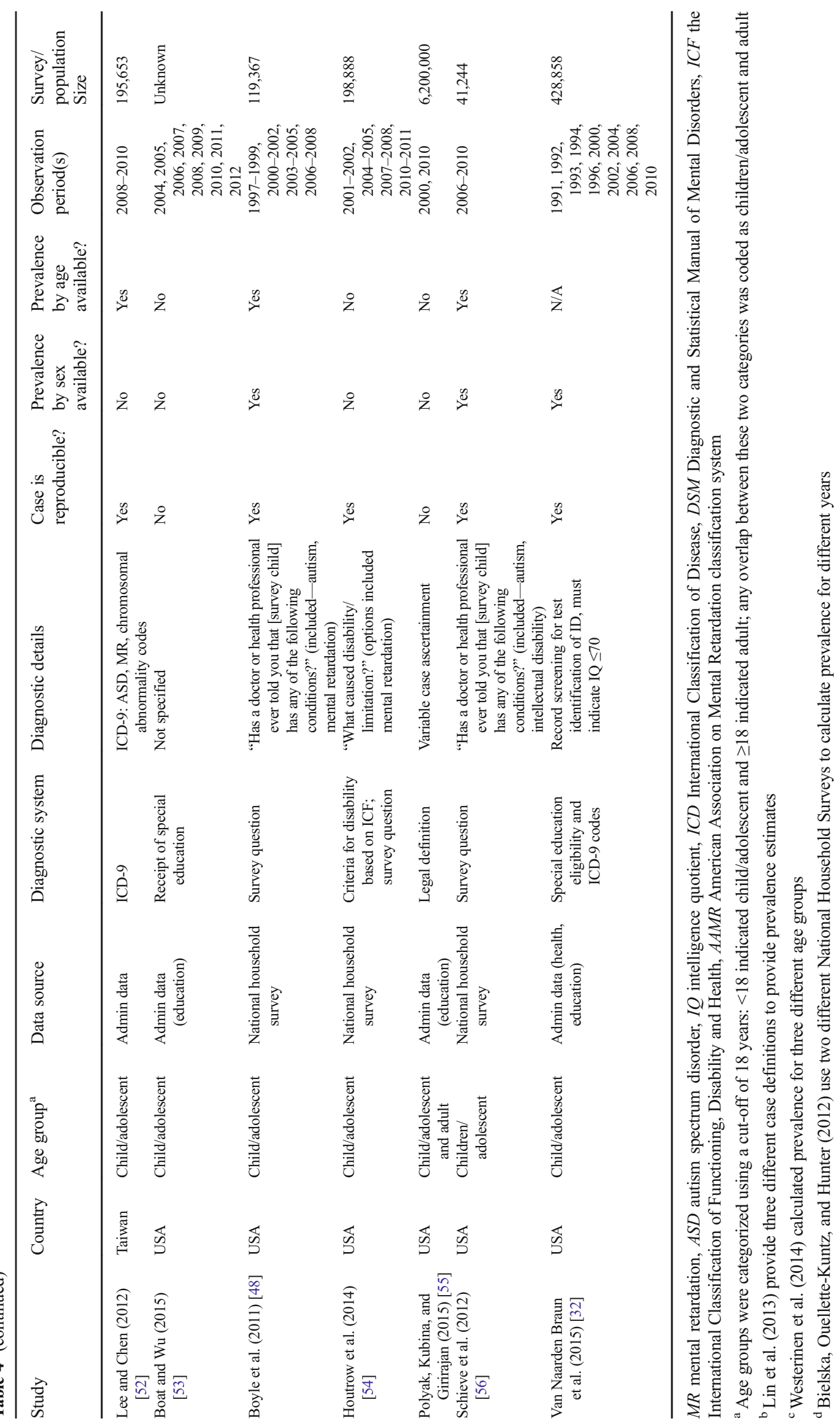




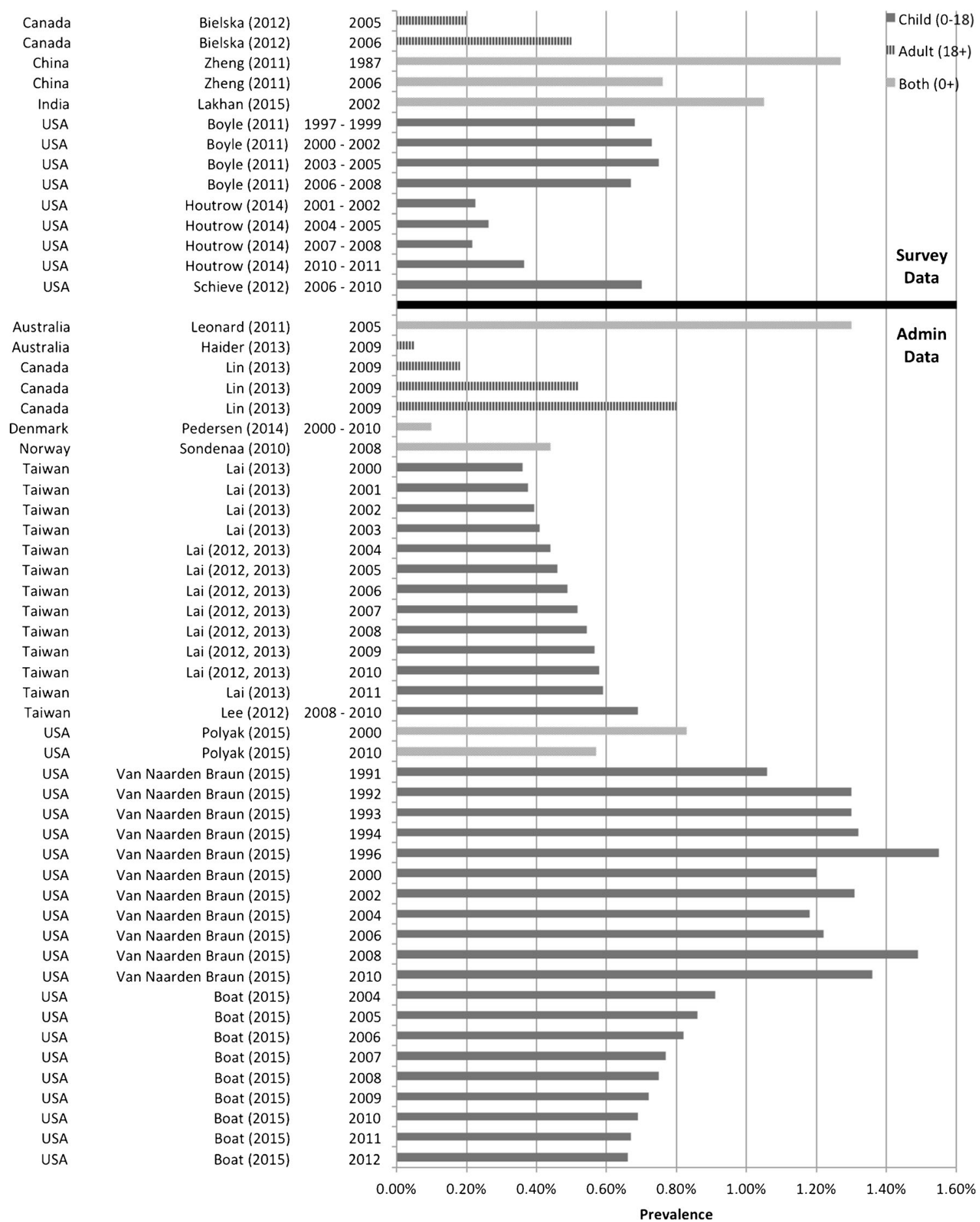

Fig. 2 Overall prevalence estimates for each of the studies

household survey in Canada. The excess prevalence in males did, however, vary considerably across the other studies. The smallest absolute difference in prevalence by sex $(0.14 \%)$ was reported in a study of children/ adolescents in Taiwan in 2004 [50•]; the greatest difference $(1.16 \%)$ was reported in a study of children/ adolescents in the United States in 2008 [32].

\section{Discussion}

The current review highlights the paucity of studies reporting on the incidence of intellectual disabilities as a whole and provides further evidence of the variability in prevalence estimates due to methodological differences including data sources, case definitions, and included age ranges. Finding 


$\begin{array}{rr}\text { Canada } & \text { Bielska (2012) } \\ \text { Canada } & \text { Bielska (2012) } \\ \text { USA } & \text { Boyle (2011) } \\ \text { Finland } & \text { Westerinen (2014) } \\ \text { Taiwan } & \text { Lai (2012) } \\ \text { Taiwan } & \text { Lai (2012) } \\ \text { Taiwan } & \text { Lai (2012) } \\ \text { Taiwan } & \text { Lai (2012) } \\ \text { Taiwan } & \text { Lai (2012) } \\ \text { Taiwan } & \text { Lai (2012) } \\ \text { Taiwan } & \text { Lai (2012) } \\ \text { USA } & \text { Van Naarden Braun (2015) } \\ \text { USA } & \text { Van Naarden Braun (2015) } \\ \text { USA } & \text { Van Naarden Braun (2015) } \\ \text { USA } & \text { Van Naarden Braun (2015) } \\ \text { USA } & \text { Van Naarden Braun (2015) } \\ \text { USA } & \text { Van Naarden Braun (2015) } \\ \text { USA } & \text { Van Naarden Braun (2015) } \\ \text { USA } & \text { Van Naarden Braun (2015) } \\ \text { USA } & \text { Van Naarden Braun (2015) } \\ \text { USA } & \text { Van Naarden Braun (2015) } \\ \text { USA } & \text { Van Naarden Braun (2015) }\end{array}$

Fig. 3 Prevalence estimates by sex

only two studies reporting incidence is not a surprise as incidence rates (in person-years) may be more indicative of access to diagnosis than actual risk of intellectual disabilities, and the lifelong nature of intellectual disabilities essentially makes the reported cumulative incidence estimates ( 0.62 to $1.58 \%$ ) proxy measures of prevalence. While a reasonable number of high quality prevalence studies have been published in the 6 years following Maulik et al.'s (2011) review [3••], the lack of comparability across studies limits the ability to corroborate results [48]. Even when studies have reported estimates for multiple years, clear time trends are not identified. Where an increase is observed, the possibility that it may reflect better identification rather than an increase in occurrence remains [51]. A consistent finding across studies is that over time, males continue to be over-represented [32, 50•].

The authors of the reviewed studies have themselves identified limitations in the methods they have used. Regarding the use of surveys, Boyle et al. (2011) acknowledge that "inaccurate reporting can result from parental distress and the stigma associated with some of the conditions; the questions may be misunderstood or there may be variations in professional terminology used" (p. 1040) [48]. Lai et al. (2013), who used a registry, note that only when the quantity and quality of services are high will administrative prevalence likely approach the true prevalence [51]. Boat and $\mathrm{Wu}$ (2015), who reported a slight drop in prevalence among children over time, point out that administrative sources such as "special education "child count" data have the advantages of being nationally representative and available annually, but do not necessarily rely on standard case definitions or diagnostic criteria that are comparable over time and across states/school districts" (p. 270) [53].

Beyond the data source, the case definition applied is also critical to the derivation of prevalence estimates. Two US studies using special education data provided different estimates for comparable years [32, 53]. Lin et al. (2015) demonstrated how different algorithms applied to the same administrative data can yield significantly different estimates of prevalence [45•].

Despite limitations associated with the different methods used (i.e., survey versus administrative data), age-specific prevalence estimates are needed to inform service planning across distinct age-related sectors (children, adults, aging). While many studies focus on an 
explicit age range, the use of standard age categories for reporting would enhance comparability. It is suggested that prevalence among 8-year-olds be a minimum requirement when presenting prevalence estimates among children as it is likely most will be identified by that age [32]. As many jurisdictions identify adults as individuals 18 years or older, 18 years should be the minimum age for reporting prevalence among adults. While new cases of intellectual disabilities are unlikely to be identified in adulthood, in light of the earlier mortality experienced in this group [58-62], it is advised to "include[e] all adults (if possible) and report in 10 year increments starting at $<25$ and extending to $>=75$ years" (p. 185) [63].

In addition to the effect of differential identification from year to year, stability in prevalence over time "might reflect a balance between increased potential for disability as more infants survive the neonatal period and reductions in other risk factors" [32] (p. 15). Of note, a review by Bosco et al. (2013) revealed that improved treatment of low birth weight infants in neonatal intensive care units was a significant contributor to the increased prevalence of intellectual disabilities [35]. In particular, Lai et al. (2013) identified intellectual disabilities and autism spectrum disorder as the largest contributors to the increasing disability prevalence in Taiwan from 2000 to 2011 [51]. As such, incidence of overall intellectual disabilities as well as those attributed to specific causes or intellectual disabilities with specific associated conditions (e.g., autism spectrum disorder) across birth cohorts should be monitored.

Through our review, we also identified a few instances of missed opportunities to report on the overall occurrence of intellectual disabilities. For example, two studies using large and nationally representative samples of children and youth analyzed data about the presence of intellectual disabilities; however, they did not provide an overall prevalence estimate $[64,65]$. When subgroups are compared, results could easily be presented in such a way as to allow the calculation of an overall prevalence thereby making an additional contribution to the body of literature.

\section{Conclusion}

Over a relatively brief observation period (6 years), a number of studies aimed at determining the prevalence of intellectual disabilities were identified across nine countries; this highlights the global desire for this knowledge. From these studies, it appears that the global prevalence of intellectual disabilities may indeed be lower than $1 \%$. The heterogeneity of studies, however, prohibits definitive conclusions about a potential downward trend. Collaborative national and international efforts to address the issues identified may be needed to ensure increased comparability across studies.

\section{Compliance with Ethical Standards}

Conflict of Interest The authors declare that they have no competing interests.

Human and Animal Rights and Informed Consent This article does not contain any studies with human or animal subjects performed by any of the authors.

\section{References}

Papers of particular interest, published recently, have been highlighted as:

- Of importance

•- Of major importance

1. Salvador-Carulla LS, Reed GM, Vaez-Azizi LM, Cooper SA, Leal $\mathrm{R}$, Bertelli M, et al. Intellectual developmental disorders: towards a new name, definition and framework for "mental retardation/ intellectual disability" in ICD-11. World Psychiatry. 2011;10(3): 175-80.

2. Tarjan G, Wright SW, Eyman RK, Keeran CV. Natural history of mental retardation: some aspects of epidemiology. Am J Ment Defic. 1973;77(4):369-79.

3.• Maulik PK, Mascarenhas MN, Mathers CD, Dua T, Saxena S. Prevalence of intellectual disability: a meta-analysis of population-based studies. Res Dev Disabil. 2011;32(2):419-36. Provides a high-quality review and meta-analysis of the global prevalence of intellectual disabilities, and reiterates an estimate of $1 \%$.

4. Flynn JR. Wechsler intelligence tests: do we really have a criterion of mental retardation. Am J Ment Defic. 1985;90(3):236-44.

5. Kanaya T, Ceci SJ, Scullin MH. The rise and fall of IQ in special ed: historical trends and their implications. J Sch Psychol. 2003;41(6): 453-65.

6. Taverna L, Bornstein MH, Putnick DL, Axia G. Adaptive behaviors in young children: a unique cultural comparison in Italy. J CrossCult Psychol. 2011;42(3):445-65.

7. Manion ML, Bersani HA. Mental retardation as a Western sociological construct: a cross-cultural analysis. Dis Han Soc. 1987;2(3): 231-45.

8. Wells K. Vineland Social Maturity Scale. In: Salkind NJ, editor. Encyclopedia of measurement and statistics. Thousand Oaks: Sage Publications; 2007. p. 1045.

9. American Psychiatric Association. Mental disorders, 1952

10. American Psychiatric Association. Diagnostic and statistical manual of mental disorders (DSM- $\left.{ }^{\circledR}\right)$. American Psychiatric Pub. 2013.

11. World Health Organization. The ICD-10 classification of mental and behavioural disorders: clinical descriptions and diagnostic guidelines. Geneva: World Health Organization; 1992.

12. Leonard H, Wen X. The epidemiology of mental retardation: challenges and opportunities in the new millennium. Ment Retard Dev Disabil Res Rev. 2002;8(3):117-34.

13. Leonard H, Dixon G, Whitehouse AJ, Bourke J, Aiberti K, Nassar $\mathrm{N}$, et al. Unpacking the complex nature of the autism epidemic. Res Autism Spectr Dis. 2010;4(4):548-54.

14. Williams JG, Higgins JPT, Brayne CEG. Systematic review of prevalence studies of autism spectrum disorders. Arch Dis Child. 2006;91(1):8. 
15. Grzadzinski R, Huerta M, Lord C. DSM-5 and autism spectrum disorders (ASDs): an opportunity for identifying ASD subtypes. Mol Autism. 2013;4(1):1

16. Coo H, Ouellette-Kuntz H, Lloyd JE, Kasmara L, Holden JJ, Lewis MS. Trends in autism prevalence: diagnostic substitution revisited. J Autism Dev Disord. 2008;38(6):1036-46.

17. Croen LA, Grether JK, Hoogstrate J, Selvin S. The changing prevalence of autism in California. J Autism Dev Disord. 2002;32(3): 207-15.

18. Crombag NM, Bensing JM, Iedema-Kuiper R, Schielen PC, Visser GH. Determinants affecting pregnant women's utilization of prenatal screening for Down syndrome: a review of the literature. J Matern-Fetal Neonatal Med. 2013;26(17):1676-81.

19. Loane M, Morris JK, Addor MC, Arriola L, Budd J, Doray B, et al. Twenty-year trends in the prevalence of Down syndrome and other trisomies in Europe: impact of maternal age and prenatal screening. Eur J Hum Genet. 2013;21(1):27-33.

20. Chitayat D, Langlois S, Wilson RD. Prenatal screening for fetal aneuploidy in singleton pregnancies. JOGC. 2011;33(7):736-50.

21. Acharya K. Prenatal testing for intellectual disability: misperceptions and reality with lessons from Down syndrome. Dev Disabil Res Rev. 2011;17(1):27-31.

22. Natoli JL, Ackerman DL, McDermott S, Edwards JG. Prenatal diagnosis of Down syndrome: a systematic review of termination rates (1995-2011). Prenat Diag. 2012;32(2):142-53.

23. Bray I, Wright DE, Davies C, Hook EB. Joint estimation of Down syndrome risk and ascertainment rates: a meta-analysis of nine published data sets. Prenat Diag. 1998;18(1):9-20.

24. Wu J, Morris JK. Trends in maternal age distribution and the live birth prevalence of Down's syndrome in England and Wales: 19382010. Eur J Hum Genet. 2013;21(9):943-7.

25. Morris JK, Wald NJ, Mutton DE, Alberman E. Comparison of models of maternal age-specific risk for Down syndrome live births. Prenat Diag. 2003;23(3):252-8.

26. Sandin S, Hultman CM, Kolevzon A, Gross R, MacCabe JH, Reichenberg A. Advancing maternal age is associated with increasing risk for autism: a review and meta-analysis. J Am Acad Child Psychiatry. 2012;51(5):477-86.

27. Hultman CM, Sandin S, Levine SZ, Lichtenstein P, Reichenberg A. Advancing paternal age and risk of autism: new evidence from a population-based study and a meta-analysis of epidemiological studies. Mol Psychiatry. 2011;16(12):1203-12.

28. Durkin M. The epidemiology of developmental disabilities in low-income countries. Ment Retard Dev Disabil Res Rev. 2002;8(3):206-11.

29. Jensen CM, Steinhausen HC, Lauritsen MB. Time trends over 16 years in incidence-rates of autism spectrum disorders across the lifespan based on nationwide Danish register data. J Autism Dev Disord. 2014;44(8):1808-18.

30. Rutherford M, McKenzie K, Johnson T, Catchpole C, O'Hare A, McClure I, et al. Gender ratio in a clinical population sample, age of diagnosis and duration of assessment in children and adults with autism spectrum disorder. Autism. 2016. doi:10.1177/1362361315617879.

31. Fombonne E. Epidemiological surveys of autism and other pervasive developmental disorders: an update. J Autism Dev Disord. 2003;33(4):365-82.

32. Van Naarden Braun K, Christensen D, Doernberg N, Schieve L, Rice C, Wiggins L, et al. Trends in the prevalence of autism spectrum disorder, cerebral palsy, hearing loss, intellectual disability, and vision impairment, metropolitan Atlanta, 1991-2010. PLoS One. 2015;10(4):e0124120.

33. Hanna-Attisha M, LaChance J, Sadler RC, Champney Schnepp A. Elevated blood lead levels in children associated with the Flint drinking water crisis: a spatial analysis of risk and public health response. Am J Public Health. 2016;106:e1-8.

34. World Health Organization. Zika: strategic response framework \& joint operations plan January-June 2016. Technical Report. 2016.
35. Brosco JP, Mattingly M, Sanders LM. Impact of specific medical interventions on reducing the prevalence of mental retardation. Arch Pediatr Adolesc Med. 2006;160(3):302-9.

36. Kodali RR, Charyulu SP. A study on the psychosocial behavior of the disabled children in Loni, Maharashtra. India J Med Sci. 2011;65(8):349.

37. Mohebbi E, Baneshi MR, Haji-Maghsoodi S, Haghdoost AA. The application of network scale up method on estimating the prevalence of some disabilities in the southeast of Iran. J Res Health Sci. 2014;14(4):272-5.

38. Wu L, Qiu Z, Wong D, Hernandez LW, Zhao Q. The research on the status, rehabilitation, education, vocational development, social integration and support services related to intellectual disability in China. Res Dev Disabil. 2010;31(6):1216-22.

39. Zheng X, Chen G, Song X, Liu J, Yan L, Du W, et al. Twenty-year trends in the prevalence of disability in China. B World Health Org. 2011;89(11):788-97.

40. Rzhetsky A, Bagley SC, Wang K, Lyttle CS, Cook Jr EH, Altman $\mathrm{RB}$, et al. Environmental and state-level regulatory factors affect the incidence of autism and intellectual disability. PLoS Comput Biol. 2014;10(3):e1003518.

41. Sandin S, Nygren KG, Iliadou A, Hultman CM, Reichenberg A. Autism and mental retardation among offspring born after in vitro fertilization. JAMA. 2013;310(1):75-84.

42. Pedersen CB, Mors O, Bertelsen A, Waltoft BL, Agerbo E, McGrath JJ, et al. A comprehensive nationwide study of the incidence rate and lifetime risk for treated mental disorders. JAMA Psychiatry. 2014;71(5):573-81.

43. Haider SI, Ansari Z, Vaughan L, Matters H, Emerson E. Health and wellbeing of Victorian adults with intellectual disability compared to the general Victorian population. Res Dev Disabil. 2013;34(11): 4034-42.

44. Leonard H, Glasson E, Nassar N, Whitehouse A, Bebbington A, Bourke J, et al. Autism and intellectual disability are differentially related to sociodemographic background at birth. PLoS One. 2011;6(3):e17875.

45. Lin E, Balogh R, Cobigo V, Ouellette-Kuntz H, Wilton AS, Lunsky Y. Using administrative health data to identify individuals with intellectual and developmental disabilities: a comparison of algorithms. J Intellect Disabil Res. 2013;57(5):462-77. Demonstrates the effect that case definition has on the prevalence reported and how minor changes in definition can lead to very different estimates.

46. Bielska IA, Ouellette-Kuntz H, Hunter D. Using national surveys for mental health surveillance of individuals with intellectual disabilities in Canada. Chronic Dis Can. 2012;32(4):194-9.

47. Westerinen H, Kaski M, Virta LJ, Almqvist F, livanainen M. Agespecific prevalence of intellectual disability in Finland at the beginning of new millennium - multiple register method. J Intellect Disabil Res. 2014;58(3):285-95.

48. Boyle CA, Boulet S, Schieve LA, Cohen RA, Blumberg SJ, Yeargin-Allsopp M, et al. Trends in the prevalence of developmental disabilities in US children, 1997-2008. Pediatrics. 2011;127(6): $1034-42$.

49. Søndenaa E, Rasmussen K, Nøttestad JA, Lauvrud C. Prevalence of intellectual disabilities in Norway: domestic variance. J Intellect Disabil Res. 2010;54(2):161-7.

50. Lai DC, Tseng YC, Hou YM, Guo HR. Gender and geographic differences in the prevalence of intellectual disability in children: analysis of data from the national disability registry of Taiwan. Res Dev Disabil. 2012;33(6):2301-7. Uses a consistent and repeatable methodology and case definition to identify that there is an increase in the prevalence of ID among children aged 3-17 over time and in what age, gender, and geographic area these changes are occurring in over time, allowing for policy and support to be implemented accordingly. 
51. Lai DC, Tseng YC, Guo HR. Trends in the prevalence of childhood disability: analysis of data from the national disability registry of Taiwan, 2000-2011. Res Dev Disabil. 2013;34(11):3766-72.

52. Lee WC, Chen TJ. Quantifying morbidity burdens and medical utilization of children with intellectual disabilities in Taiwan: a nationwide study using the ACG case-mix adjustment system. Res Dev Disabil. 2012;33(4):1270-8.

53. Boat TF, Wu JT. Prevalence of intellectual disabilities. In: Mental disorders and disabilities among low-income children. National Academies of Sciences, Engineering, and Medicine. Washington, DC: The National Academies Press, 2015. doi: 10.17226/21780.

54. Houtrow AJ, Larson K, Olson LM, Newacheck PW, Halfon N. Changing trends of childhood disability, 2001-2011. Pediatrics. 2014;134:530-8.

55. Polyak A, Kubina RM, Girirajan S. Comorbidity of intellectual disability confounds ascertainment of autism: implications for genetic diagnosis. Am J Med Genet B Nueropsychiatr Genet. 2015;168(7):600-8.

56. Schieve LA, Gonzalez V, Boulet SL, Visser SN, Rice CE, Braun $\mathrm{KV}$, et al. Concurrent medical conditions and health care use and needs among children with learning and behavioral developmental disabilities, National Health Interview Survey, 2006-2010. Res Dev Disabil. 2012;33(2):467-76.

57. Lakhan R, Ekúndayò OT, Shahbazi M. An estimation of the prevalence of intellectual disabilities and its association with age in rural and urban populations in India. J Neurosci Rural Pract. 2015;6(4): 523.
58. Ouellette-Kuntz H, Shooshtari S, Balogh R, Martens P. Understanding information about mortality among people with intellectual and developmental disabilities in Canada. J Appl Res Intellect Disabil. 2015;28(5):423-35.

59. Heslop P, Lauer E, Hoghton M. Mortality in people with intellectual disabilities. J Appl Res Intellect Disabil. 2015;28(5):367-72.

60. Lauer E, McCallion P. Mortality of people with intellectual and developmental disabilities from select US State disability service systems and medical claims data. J Appl Res Intellect Disabil. 2015;28(5):394-405.

61. Florio T, Trollor J. Mortality among a cohort of persons with an intellectual disability in New South Wales. Aust J Appl Res Intellect. 2015;28(5):383-93.

62. McCarron M, Carroll R, Kelly C, McCallion P. Mortality rates in the general Irish population compared to those with an intellectual disability from 2003 to 2012 . J Appl Res Intellect Disabil. 2015;28(5):406-13.

63. Ouellette-Kuntz H, Martin L, McKenzie K. A review of health surveillance in older adults with intellectual and developmental disabilities. Int Rev Res Dev Disabil. 2015;48:151-94.

64. Singh GK, Yu SM, Kogan MD. Health, chronic conditions, and behavioral risk disparities among US immigrant children and adolescents. Public Health Rep. 2013;1:463-79.

65. Prasad AN, Burneo JG, Corbett B. Epilepsy, comorbid conditions in Canadian children: analysis of cross-sectional data from cycle 3 of the national longitudinal study of children and youth. Seizure. 2014;23(10):869-73. 